\title{
PENGENALAN LITERASI KEUANGAN PADA YAYASAN TAHFIDZUL QUR'AN AR-RAHMANI
}

\author{
Siti Alifah ${ }^{1}$, Adhis Darussalam Pamungkas ${ }^{2}$ Lengsi Manurung ${ }^{3}$ \\ Program Studi Pendidikan Ekonomi, Fakultas Ilmu Pendidikan dan Pengetahuan Sosial, \\ Universitas Indraprasta \\ e-mail: adhis.darussalam.pamungkas@gmail.com
}

\begin{abstract}
Abstrak
Tujuan kegiatan ini adalah untuk mengajarkan siswi mengenai literasi keuangan, yaitu mengelola uang dengan bijaksana dan pentingnya menabung untuk masa depan,metode yang digunakan dalam pengabdian masyarakat ini adalah dengan menulis dan berhitung sambil bermain, materi terdiri dari, mengenal nilai uang, mengelola uang dengan benar, memilih antara kebutuhan dengan keinginan (3) merencanakan keuangan untuk keperluan di masa depan (4) pentingnya menabung . Kegiatan dilaksanakan di Pesantren milik Yayasan Tahfidzul Qur'an Ar-Rahmani, Ciputat, Tangerang Selatan dengan peserta yang berjumlah 22 orang siswi. Hasil dari hari pertama pengabdian adalah 14 peserta sudah terliterasi, kemudian 6 orang peserta masih kurang terliterasi, dan 2 anak belum memiliki pemahaman tentang literasi keuangan. Kemudian setelah dilakukan sosialisasi, pada hari kedua kelompok pengabdian mengadakan evaluasi dan hasilnya semua peserta paham betapa pentingnya mengelola keuangan, serta menggunakan uang sakunya dengan bijak, mengapa harus memiliki tabungan, melakukan skala prioritas dalam menggunakan uangnya, kemudian para peserta juga menyatakan telah mencoba untuk mengelola keuangannya sendiri.
\end{abstract}

Kata kunci: Literasi Keuangan, Keuangan, Tabungan, Siswi.

\begin{abstract}
The purpose of this activity is to teach students about financial literacy such as managing financial wisely and the importance of saving for the future. The method used in this community service is by writing and counting while playing. The material consists of understanding the value of money, managing money properly, choosing between needs and desires, financial planning for future need, and the importance of saving. The activity was carried out at Boarding School owned by the Tahfidzul Qur 'an Ar-Rahmani Foundation, Ciputat, South Tangerang with a total of 22 students. The participants were very enthusiastic listening to the material presented by the community service groups. The results of the financial literacy level survey showing there are participants who do not know anything about financial institutions, products, services, rights, risks, etc. Then the results of the evaluation of the level of financial literacy are the participants have made significant progress in terms of the level of financial literacy. Participants try to recalculate expenses and income so that they can managed money to save, determine the priority needs, etc.
\end{abstract}

Keywords: Financial Literacy, Finance, Saving, Student.

\section{PENDAHULUAN}

Dewasa ini pesantren tidak hanya dituntut untuk dapat menghasilkan santri yang pintar dalam bidang agama, dan juga memiliki wawasan umum yang baik. Salah satu wawasan yang harus dimiliki adalah mengenai literasi keuangan. Pendidikan literasi keuangan adalah hal penting yang harus diberikan kepada anak-anak, supaya tidak menjadi generasi yang konsumtif. Mengarahkan anak untuk mengelola keuangan yang benar merupakan salah satu tujun penting dalam pendidikan literasi keuangan. Pendidikan literasi keuangan juga memiliki tujuan jangka panjang yaitu untuk menambah wawasan dan kemampuan literasi anak, atau dari yang sebelumnya 
kurang literasi menjadi paham dengan konsep literasi keuangan, selain itu pendidikan literasi juga bertujuan untuk meningkatkan kesadaran akan kehadiran lembaga keuangan yang berada di tengah - tengah masyarakat. Selanjutnya pengabdian masyarakat yang dilakukan oleh Sadri (2019) menyimpulkan, anak-anak memiliki tingkat literasi keuangan yang rendah, memahami uang hanya untuk konsumtif (jajan atau membeli mainan atau sesuai dengan keinginan), mereka tidak memahami perbedaan kebutuhan dan keinginan, orang tua mereka tidak mengajarkan pentingnya menabung atau menggunakan uang saku dengan baik. Pelaksanaan Edukasi dalam rangka meningkatkan keuangan masyarakat sangat diperlukan karena berdasarkan survei yang dilakukan oleh OJK pada 2013, bahwa tingkat literasi keuangan penduduk Indonesia dibagi menjadi empat bagian, yatu:

1. Well literate, yakni memiliki pengetahuan dan keyakinan tentang lembaga jasa keuangan serta produk jasa keuangan, termasuk fitur, manfaat dan risiko, hak dan kewajiban terkait produk dan jasa keuangan, serta memiliki keterampilan dalam menggunakan produk dan jasa keuangan.

2. Sufficient literate, memiliki pengetahuan dan keyakinan tentang lembaga jasa keuangan serta produk dan jasa keuangan, termasuk fitur, manfaat dan risiko, hak dan kewajiban terkait produk dan jasa keuangan.

3. Less literate, hanya memiliki pengetahuan tentang lembaga jasa keuangan, produk dan jasa keuangan.

4. Not literate, tidak memiliki pengetahuan dan keyakinan terhadap lembaga jasa keuangan serta produk dan jasa keuangan, serta tidak memiliki keterampilan dalam menggunakan produk dan jasa keuangan.

Pengenalan kepada anak mengenai perbedaan antara kebutuhan dan keinginan juga akan berdampak baik untuk pengelolaan keuangannya. Pada usia anak sangat diperlukan wawasan dan keterampilan dasar untuk mengambil keputusan pribadi yang penting bagi dirinya. Akan tetapi hal tersebut jarang didapatkan baik dari keluarga ataupun sekolah. Setiap manusia memiliki siklus hidup sehingga apa yang dilakukannya akan menjadi penentu kesejehteraan di masa depan, apa yang terjadi di masa depan adalah buah dari masa lalu yang mereka usahakan. Semakin baik dalam mengelola dan merencanakan keuangan maka risiko mengalami permasalahan keuangan di masa depan akan semakin kecil.

Pesantren adalah tempat santri belajar dan mendalami agama tetapi juga sebagai tempat untuk beraktivitas mengembangkan potensi dasar untuk membangun karakter positifnya. Wadah ini sangat baik karena memiliki visi-misi membangun pemuda agar dapat hidup lebih baik atau lebih sejahtera. Begitu juga dengan literasi keuangan jika mampu dipraktekkan akan berdampak signifikan bagi kehidupan anak. Mengenalkan finansial kepada para santri bukan hanya tentang uang. Tetapi santri juga turut andil dalam keputusan keuangan, dan yang terpenting adalah santri harus mengenal konsep nilai. Setelah itu, maka santri akan memiliki pandangan yang benar ketika mengelola keuangan.

Selain unggul dalam bidang agama, melalui pembelajaran mengenai literasi keuangan ini diharapkan Yayasan Tahfidzul Qur'an Ar-Rahmani dapat mencetak generasi yang juga unggul dalam wawasan mengenai literasi keuangan. Pondok pesantren Tahfidzul Qur'an Ar-rahmani memiliki 22 santri yang semuanya adalah perempuan.

\section{METODE}

PKM ini dilaksanakan dengan beberapa tahapan kegiatan yang berkesinambungan. Pertama, dilakukan observasi langsung di Yayasan Tahfidzul Qur'an Ar-Rahmani, Ciputat, Tangerang Selatan. Kemudian dilakukan survei dengan cara diskusi dan wawancara langsung terhadap santri yang berada di yayasan tersebut, setelah dilakukan observasi disimpulkan bahwa terdapat 22 santriwati/siswi. Sasaran pengabdian masyarakat ini langsung kepada Siswi di pondok pesantren Tahfidzul Qur'an Ar-Rahmani. Tahapan selanjutnya yaitu, mempersiapkan materi yang akan disosialisasikan, menyusun jadwal pelaksanaan pendidikan, pembagian tugas kepada tim pengabdian masyarakat.

Observasi dan survei dilakukan bulan Desember 2019 dengan bertemu ketua yayasan sekaligus memberitahukan tujuan pelaksanaan pengabdian ini, kemudian sosialisasi dilakukan 
pada bulan Februari 2020 selama 2 hari. Kelompok pengabdian masyarakat berasal dari Universitas Indraprasta, terdiri dari 1 orang dosen pendidikan ekonomi, 1 orang dosen teknik industri, dan 1 orang mahasiswa dari program pendidikan ekonomi. Peserta pengabdian ini adalah 22 orang siswi, umur para siswi tersebut variatif dari mulai dari 11 tahun - 18 tahun, dan para siswi tersebut juga mendapat pendidikan formal diluar yayasan dari mulai SD SMA. Kelompok pengabdian menggunakan dana pribadi dalam melakukan sosialisasi ini.

Kelompok pengabdian mengajarkan materi yang terdiri dari (1) mengenal uang (2) pentingnya menabung (3) mengenalkan lembaga keuangan, produk, manfaat, risiko, dsb. (4) skala prioritas dalam megelola keuangan. Sosialisasi disampaikan dengan cara belajar, membaca, berhitung sambil bermain, serta pada akhir acara dilakukan tanya jawab antara peserta dengan kelompok pengabdian masyarakat. Sosialisasi juga dibantu oleh aplikasi power point dan Video durasi pendek.

\section{HASIL DAN PEMBAHASAN}

Pada hari pertama sosialisasi dimulai dengan berdoa, kemudian selanjutnya penyampaian materi literasi keuangan melalui video pengetahuan pentingnya menabung sejak dini dan bernyanyi bernyanyi bersama untuk menghangatkan suasana. Setelah diberikan wawasan melalui video yang berisi tentang ajakan menabung dan mengatur keuangan dengan baik sejak dini, kemudian peserta diminta untuk menghitung pengeluaran uangnya. Para peserta selanjutnya diajak untuk menghapus pengeluaran yang tidak perlu, setelah selesai maka penyaji acara akan memberikan celengan untuk latihan menabung. Di akhir acara kelompok pengabdian masyarakat memberikan pertanyaan dalam bentuk tertulis pada setiap peserta, pertanyaan terebut adalah mengenai pengetahuan dan keyakinan terhadap lembaga jasa keuangan, produk, fitur, manfaat dsb. Kegiatan pengabdian didokumentasikan melalui foto - foto:

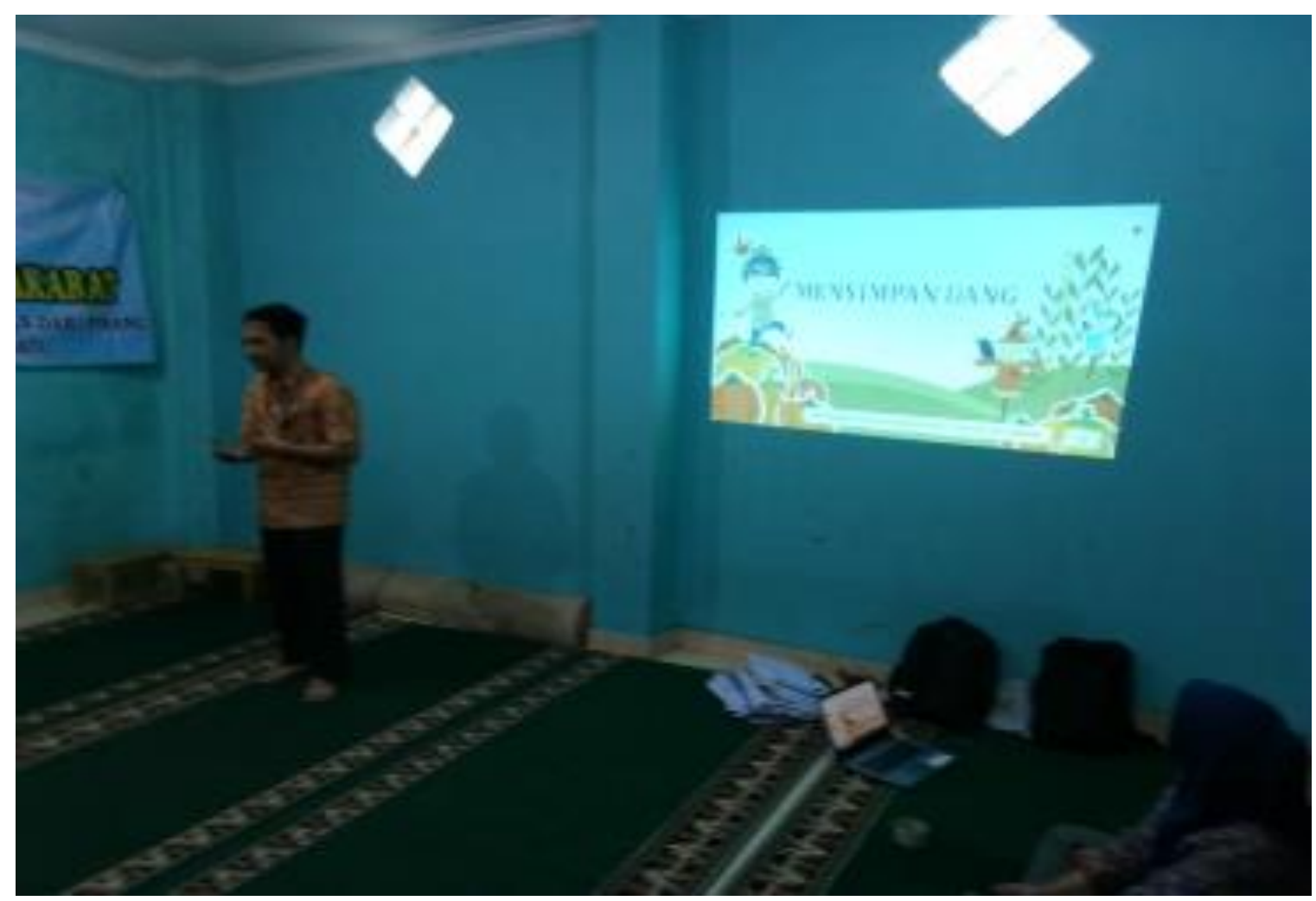

Gambar 1

Kelompok Pengabdian Masyarakat Sedang Menyampaikan Salah Satu Materi 


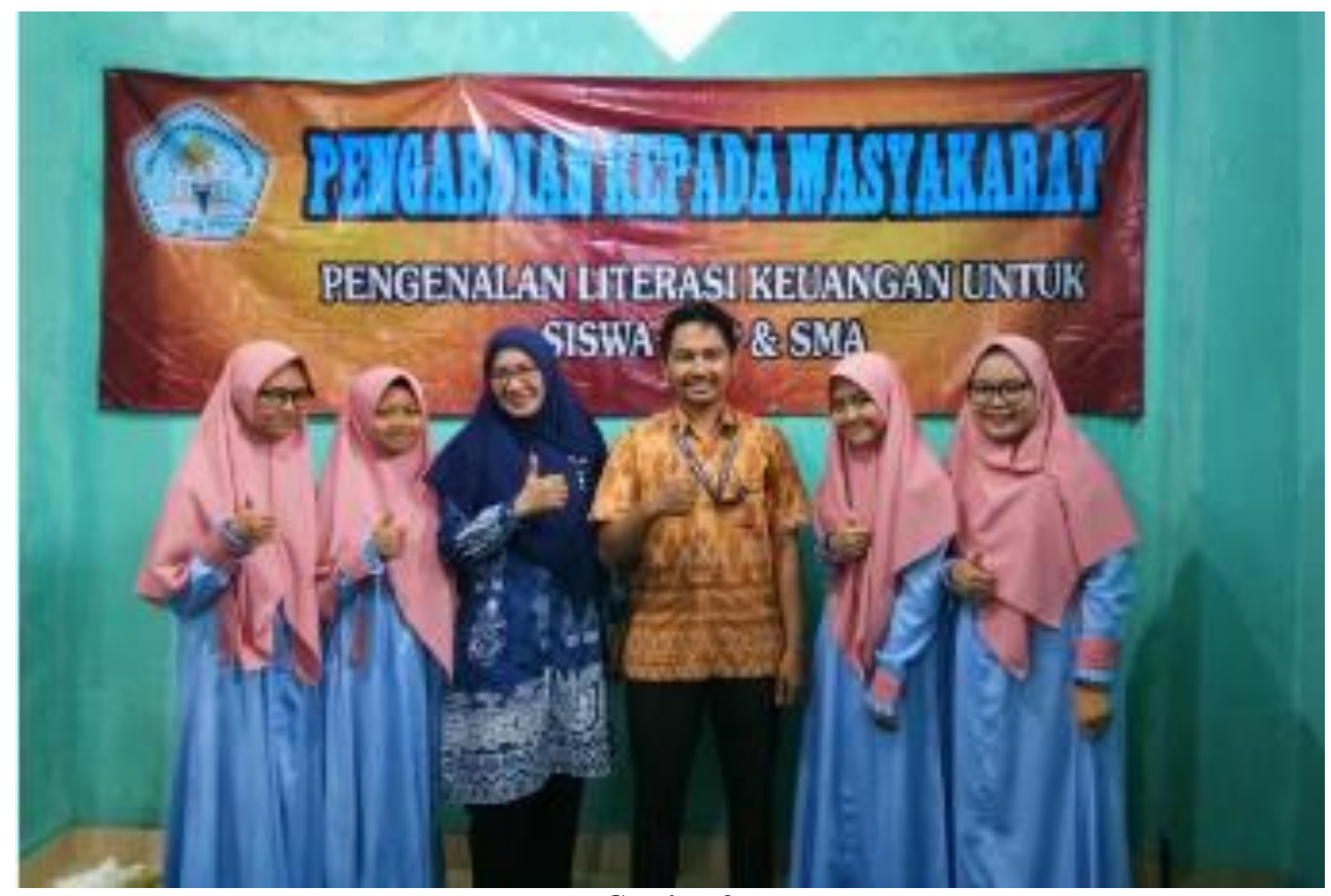

Gambar 2

Kelompok Pengabdian Masyarakat Melakukan Sesi Foto Bersama Dengan Beberapa Peserta

Hasil tanya jawab dengan peserta dijabarkan dalam tabel 1 dibawah ini, indikator tingkat literasi keuangan bersumber dari Otoritas Jasa Keuangan yang dibagi kedalam 4 kategori:

Tabel 1

Hasil Survei Tingkat Literasi Keuangan

\begin{tabular}{|l|c|c|c|c|}
\hline Indikator & Well Literate & $\begin{array}{c}\text { Sufficient } \\
\text { Literate }\end{array}$ & Less Literate & Not Literate \\
\hline Peserta & 16 & 2 & 2 & 2 \\
\hline
\end{tabular}

Sumber: Kelompok Pengabdian Masyarakat, diolah.

Berdasarkan tabel 1 disimpulkan bahwa:

1. Well literate (11 Peserta), yakni memiliki pengetahuan dan keyakinan tentang lembaga jasa keuangan serta produk jasa keuangan, termasuk fitur, manfaat dan risiko, hak dan kewajiban terkait produk dan jasa keuangan, serta memiliki keterampilan dalam menggunakan produk dan jasa keuangan. Para peserta ini memang sudah menggunakan produk bank untuk keperluan transfer dan menabung.

2. Sufficient literate (2 peserta), memiliki pengetahuan dan keyakinan tentang lembaga jasa keuangan serta produk dan jasa keuangan, termasuk fitur, manfaat dan risiko, hak dan kewajiban terkait produk dan jasa keuangan. Para peserta merasa belum membutuhkan produk jasa keuangan.

3. Less literate ( 2 peserta), hanya memiliki pengetahuan tentang lembaga jasa keuangan, produk dan jasa keuangan.

4. Not literate ( 2 peserta), tidak memiliki pengetahuan dan keyakinan terhadap lembaga jasa keuangan serta produk dan jasa keuangan, serta tidak memiliki keterampilan dalam menggunakan produk dan jasa keuangan.

Hari kedua sosialisasi, kelompok pengabdian masyarakat melakukan evaluasi dan disimpulkan bahwa terdapat kemajuan signifikan terhadap pemahaman peserta tentang literasi keuangan, kelompok pengabdian masyarakat juga melakukan sesi motivasi para peserta supaya 
lebih semangat untuk menabung dan lebih cakap dalam mengelola keuangannya. Hasil dari evaluasi penulis sajikan pada tabel 2 dibawah ini:

\section{Tabel 2}

Hasil Evaluasi Tingkat Literasi Keuangan

\begin{tabular}{|l|c|c|c|c|}
\hline Indikator & Well Literate & $\begin{array}{c}\text { Sufficient } \\
\text { Literate }\end{array}$ & Less Literate & Not Literate \\
\hline Peserta & 18 & 4 & - & - \\
\hline
\end{tabular}

Sumber: Kelompok Pengabdian Masyarakat, diolah.

Hasil Evaluasi Tingkat Literasi Keuangan adalah:

1. Well literate (17 Peserta), yakni memiliki pengetahuan dan keyakinan tentang lembaga jasa keuangan serta produk jasa keuangan, termasuk fitur, manfaat dan risiko, hak dan kewajiban terkait produk dan jasa keuangan, serta memiliki keterampilan dalam menggunakan produk dan jasa keuangan.

2. Sufficient literate (3 peserta), memiliki pengetahuan dan keyakinan tentang lembaga jasa keuangan serta produk dan jasa keuangan, termasuk fitur, manfaat dan risiko, hak dan kewajiban terkait produk dan jasa keuangan.

3. Less literate (0 peserta), hanya memiliki pengetahuan tentang lembaga jasa keuangan, produk dan jasa keuangan.

4. Not literate ( 0 peserta), tidak memiliki pengetahuan dan keyakinan terhadap lembaga jasa keuangan serta produk dan jasa keuangan, serta tidak memiliki keterampilan dalam menggunakan produk dan jasa keuangan.

Berdasarkan hasil evaluasi, kemajuan yang dialami cukup signifikan karena 2 peserta yang sebelumnya masuk dalam kategori "Not Literate" dan 2 peserta yang masuk dalam kategori "Less Literate" kini sudah masuk kedalam kategori "Sufficient Literate". Sedangkan 2 peserta yang sebelumnya ada pada tingkatan "Sufficient Literate" saat ini sudah masuk dalam kategori "Well Literate".

\section{SIMPULAN}

Para peserta sangat antusias mendengarkan materi yang disampaikan oleh kelompok pengabdian masyarkat. Hasil survei tingkat literasi keuangan pada tabel 1 diatas menunjukkan masih ada peserta yang sama sekali belum mengetahui tentang lembaga keuangan, produk, layanan, hak, kewajiban, risiko, dsb.

Kemudian hasil evaluasi tingkat literasi keuangan pada tabel 2 diatas menyimpulkan, peserta sudah mengalami kemajuan signifikan dalam hal tingkat literasi keuangan. Para peserta mencoba menghitung ulang pengeluaran dan pemasukan uang agar dapat dikelola dengan baik serta bisa menyisihkan untuk menabung, menentukan prioritas kebutuhan, dll.

\section{SARAN}

Saran untuk pengabdian masyarakat sejenis di kemudian hari adalah, mengajak para orang tua dan guru di pesantren ataupun di sekolah untuk turun tangan secara langsung dalam membimbing dan memberikan wawasan mengenai literasi keuangan, karena mengelola keuangan harus dilakukan secara berkesinambungan. Menurut Asnawi, dkk (2019) Pentingnya literasi keuangan ditanamkan sejak dini sehingga pola konsumtif data dicegah sejak dini, anak-anak sejak dini diharapkan sudah mengenal konsep menabung, mempraktekkan dan selanjutnya membuat keputusan dalam melakukan keputusan pembelanjaan.

\section{UCAPAN TERIMA KASIH}

Ucapan terima kasih penulis sampaikan kepada pihak ketua yayasan Tahfidzul Qur'an Ar-Rahmani khususnya siswi yang menerima kehadiran dan antusias menjalani kegiatan pengabdian masyarakat. Terima kasih juga kepada mahasiswa yang membantu program pengabdian masyarakat ini. 


\section{DAFTAR PUSTAKA}

Ati, A. P., \& Widiyarto, S. Literasi Bahasa Dalam Meningkatkan Minat Baca Dan Menulis Pada Siswa Smp Kota Bekasi. Basastra, 9(1), 105-113.

Budiono, Tania. (2014). Keterkaitan Financial Attitude, Financial Behaviour \& Financial Knowledge pada Mahasiswa Strata 1 Universitas Atmajaya Yogyakarta. Yogyakarta: Universitas Atmajaya

Kanserina, Dias. (2015). Pengaruh Literasi Ekonomi dan Gaya Hidup Terhadap Perilaku Konsumtif Mahasiswa Jurusan Pendidikan Ekonomi UNDIKSHA 2015. Jurnal Singaraja: Undiksha.

Kasmir. (2012). Bank dan Lembaga Keuangan Lainnya. Jakarta: RajaGrafindo Persada.

Literasi Keuangan. (2013). Otoritas Jasa Keuangan. Diunduh dari: https://www.ojk.go.id/id/kanal/edukasi-dan-perlindungan-konsumen/Pages/LiterasiKeuangan.aspx tanggal 4 Februari 2020.

Nainggolan, Pahala. (2012). Manajemen Keuangan Lembaga Nirlaba. Yayasan Bina Integrasi Edukasi (YBIE).

Rapih, S. (2016). Pendidikan Literasi Keuangan Pada Anak: Mengapa dan Bagaimana?. Scholaria, 6(2), 14-28.

Rasyid, Roseni (2012). Analisis Tingkat Literasi Keuangan Mahasiswa Program Studi Manajemen Fakultas Ekonomi Universitas Negeri Padang. Jurnal Kajian Manajemen Bisnis, 1(12).

Remund, David L. (2010). Financial Literacy Explicated: The Case for a Clearer Definition in an Increasingly Complex Economy. The Journal of ConsumerAffairs, 44(2).

Suprapto, H. A. (2018). PELATIHAN Pembuatan Proposal Rencana Bisnis (Business Plan) Bagi Siswa Madrasah Tsanawiyah Nurul Hikmah Dan Smp Al-Ihsan Guna Meningkatkan Kemampuan Berwirausaha. Abdimas Siliwangi, 1(2), 81-88.

Sadri, Muhammad. (2019). Pemberdayaan siswa melalui edukasi keuangan sejak dini sebagai upaya pembentukan karakter cerdas mengelola uang. Seminar Nasional Kewirausahaan, 1(1), 290-295. http://doi.org/10.30596/snk.vlil.3630

Saerang, I.S., \& Maramis, J.B. (2017). Eksplorasi respon perencanaan dan pengelolaan keuangan keluarga, Jurnal manajemen bisnis dan inovasi, 4(2). 110 - 115.

Sunarmintyastuti, L., \& Widiyarto, S. (2019). Pelatihan Pembuatan Prakarya Dalam Rangka Meningkatkan Minat Berwirausaha Siswa. Matappa: Jurnal Pengabdian Kepada Masyarakat, 2(2), 134-137.

Sunarmintyastuti, L., \& Suprapto, H. A. (2020). Pengembangan SDM Melalui Minat dan Motivasi Santriwati pada Yayasan Taufidzul Qur'an Ar-Rahmani di Ciputat Tangerang Selatan. JURNAL ILMIAH WAHANA PENDIDIKAN, 6(2), 104-109.

Vernia, D. M., Widiyarto, S., Narsih, D., \& Tiwinyanti, L. (2020). Sosialisasi Dan Pembekalan Strategi Pemasaran Produk Olahan Pisang Pada Siswa Pondok. Jurnal Pengabdian UntukMu NegeRI, 4(1), 125-128.

Vernia, D. M., Suprapto, H. A., \& Supandi, A. (2018). Penyuluhan Pentingnya Minat Kewirausahaan Dalam Membentuk Karakter Mandiri Siswa Smk Insan Mulia dan SMP Azzuhriyah Kota Bekasi. MATAPPA: Jurnal Pengabdian Kepada Masyarakat, 1(2), 54-59.

Widiyarto, S., Wulansari, L., \& Hasanusi, F. S. (2020). Pelatihan "English Communicative" Guna Mempersiapkan SDM Berkualitas dan "Competitive". Intervensi Komunitas, 1(2), 125-131. 